\title{
Evaluation of laparoscopic appendectomy proficiency in the management of acute appendicitis based on anatomy and pathologies
}

\begin{tabular}{ccc}
\hline Suhel M. Najjar $^{1 *}$ & J awher Taher Aumer $^{1}$ & Paiman J amal Muhamad $^{1}$ \\
\hline Abstract
\end{tabular}

Background and objective: Laparoscopic appendectomy entered a controversial dilemma for choosing a perfect approach for appendectomy. Evaluation studies may resolve this controversy. This study aimed to evaluate laparoscopic appendectomy proficiency depending on anatomy and pathology.

Methods: A total of 148 cases managed by laparoscopic appendectomy were studied from 2014 to 2015.These cases were diagnosed clinically and by investigations. Parameters studied were operation duration, conversion rate, complications, associated pathology, rehabilitation, and histopathology.

Results: By laparoscopy, the anatomical position of the appendix was easily recognized in $83.78 \%$ of cases, while the position of $16.22 \%$ of cases was difficult because of the hidden appendix by adhesions, complications, and technical causes. The operation duration ranged between 34 and 60 minutes. Associated pathologies were demonstrated in $8 \%$ of cases. Regarding discharge from the hospital, $30 \%$ were on the same day, $50 \%$ on the first postoperative day, and $20 \%$ on the second postoperative day. Postoperative complications were $3 \%$ due to pelvic hematoma, port site infection, and bleeding. Postoperative pain was experienced in $3 \%$ of cases. The conversion rate was $4.7 \%$. Rehabilitation was within $8-10$ days.

Conclusions: Laparoscopic appendectomy is safe and suitable for various anatomical positions of the inflamed appendix, suspicious, hidden, and in the presence of other pathologies with a properly placed port can play diagnostic and therapeutic roles. Significant superiority of laparoscopic appendectomy was observed in this study for the management of acute appendicitis and its pathological consequences. The conversion rate was $4.7 \%$ due to other pathologies.

Keywords: Laparoscopic; Appendectomy; Anatomy; Pathology.

\section{Introduction}

Only $40-65 \%$ of acute appendicitis are presented by typical acute appendicitis clinical features. Therefore, several clinical scores have been developed, including the Alvarado score, also known as the MANTRELS score, which helps for the correct diagnosis of acute appendicitis. Alvorado score in adults and Emergency Department Point-of-Care Ultrasound (ED-POCUS) in the diagnosis of acute appendicitis in emergency department pediatric patients provide immediate benefit in the diagnosis of acute appendicitis with a sensitivity of $81.25 \%$ and a correct predictive value of $74.28 \%{ }^{1,2}$ The development of laparoscopic surgery yielded by close interaction between technology and the medical-surgical innovators permitted the rapid evolution of laparoscopic surgery during the last two decades not only for managing acute appendicitis but its rule in diagnosis and treating non-suspected pathologies with less morbidity. ${ }^{2,3}$ With the introduction of laparoscopy techniques, the zone of surgical management has changed, from the era of the objection of key-hole surgery

${ }^{1}$ Department of Basic Sciences, College of Medicine, Hawler Medical University, Erbil, I raq.

* Correspondence: suhelnajjar6063@gmail.com 
and the character of big surgeons do a big incision in the past 30 years to the era of minimally invasive surgery. This had also been criticized by other authors that the idea of large problems requires large incisions so deeply dominated surgical thinking that there was little room to appreciate the advances of "key-hole" surgery had been repressed. Working against this current, some general surgeons took up the challenge. ${ }^{3,4}$ The advent and rapid acceptance of laparoscopic surgery led to the idea of performing a laparoscopic appendectomy. In 1983 Semm, a German gynecologist, performed the first laparoscopic appendectomy. ${ }^{3-5}$ Variability of the position of the appendicular tips produced variable clinical features that required a wider visualization of the abdominal cavity in order to be deal with the procedure of appendicectomy. This had been advocated as the preferred approach. ${ }^{6}$ Kurt Semm used laparoscopy as a diagnostic and therapeutic tool and regarded that laparoscopy is the only way for a surgeon to be able to view the entire abdomen and to direct his procedure accordingly. ${ }^{5-7}$ There is a controversial view for the laparoscopic appendectomy and open appendectomy as documented by some surgeons. Whether or not there is a benefit to laparoscopy versus open appendectomy in the management of acute appendicitis remains a subject of controversy despite the publication of numerous randomized studies. The advantages are most evident in the young female, the employed patient, and the obese patient. Overall, the more evaluations of laparoscopic appendectomy advised as the advantages of laparoscopy are, at best, modest and clinical benefit is not always demonstrable, the risk remains an unknown and should be evaluated by further studies., ${ }^{5,8}$ Regarding the controversy of laparoscopic appendectomies, it is also mentioned that laparoscopic appendectomy has some disadvantages, such as long operative time and the possibility of serious complications, but generally accelerates postoperative early recovery to shorten hospitalization..$^{7-9}$ The other idea in these controversies is that laparoscopic appendectomy for complicated appendicitis is feasible and safe. It is associated with less postoperative pain, lower incidence of infectious complications, and reduced length of hospital stay when compared with patients who had an open appendectomy. ${ }^{9}$ The patients who had previous surgery should be considered as a risk population for complications of gas gangrene which had been cited and recorded by laparoscopic surgeries and advice close monitoring of cardiac rhythm during insufflation of carbon dioxide. ${ }^{10,11}$ Anyhow by the time the previous abdominal surgeries, which thought as a limiting border for laparoscopic procedures, had found no any negative effect on the laparoscopic appendectomy as proved by a study which manifested that previous abdominal surgery, whether upper or lower abdominal, has no significant impact on laparoscopic appendectomy for acute appendicitis. $^{12}$ Other previous studies had revealed that not every case of appendicitis could be managed laparoscopically. Nevertheless, patients who require conversion to open appendectomy are those with the presence of periappendiceal fluid or an inflammatory mass or abscess, which tend to have high computed tomographic inflammation grades. ${ }^{13}$ On the other hand, some other studies give no any advantages or superiority of laparoscopic appendectomy. 9,11,13,14 This study aimed to prove or resolve controversial concepts regarding laparoscopic appendectomy management of acute appendicitis depending on anatomical and pathological findings according to global management rules and our locality demands.

\section{Methods}

In this retrospective study, laparoscopic appendectomies were performed on 148 cases of acute appendicitis from March $1^{\text {st }}$, 
2014, to April 20 ${ }^{\text {th }}$, 2015. Most cases were diagnosed or highly suspected of having acute appendicitis by all a known appendicitis clinical scores, laboratory findings, mainly complete blood count, and ultrasound .In these cases, three midline small abdominal incisions were used, as seen in Figure 1. Through the supra-umbilical incision, a $10 \mathrm{~mm}$ port was introduced for endoscopy and appendix extraction. The other incisions two for $5 \mathrm{~mm}$ ports (sub umbilical and suprapubic) for manipulating instruments mainly Maryland, grasper forceps Endoloops moreover to Harmonic or ligasure electrosealings instruments. Preoperatively all the cases were covered by antimicrobials (cefotaxim $1 \mathrm{gm}$ and metronidazole $500 \mathrm{mg}$ ) intravenously six hours preoperatively. Peroperatively, the bed of the removed appendix and around incisions in the abdominal wall was infiltrated by bupivacaine $(10 \mathrm{ml}$ of $5 \mathrm{mg} / \mathrm{ml})$. Parameters studied were the duration of operation, conversion rate, positions of the appendix, intraoperative and postoperative complications, concomitant second pathologies, postoperative complications, and hospitalization time. The statistical package for the social sciences (SPSS, version 21) was used for data analysis. Independent-sample $t$ test was used to compare the means of two groups. The level of significance was set at $(P \leq 0.05)$.

\section{Results}

Patient's Alvorado score of acute appendicitis diagnosis ranged between 6 and 9, meaning suspicious or highly suspicious. The age of the patients ranged from 8 to 26 years. The male:female ratio was 2.5:1. The applied areas for mentioned ports were very safely applicable and controllable (Figure 1).

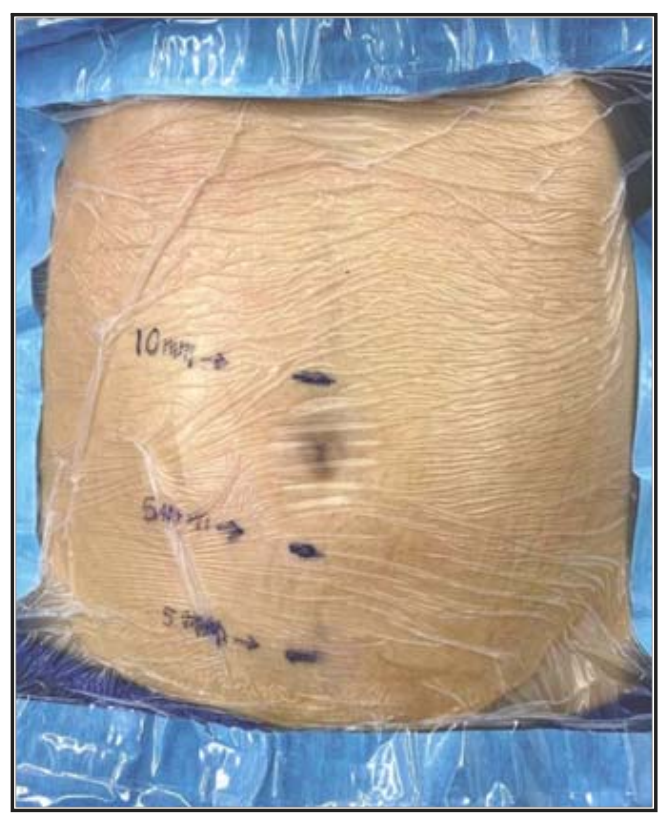

Figure 1: Used ports sites 
In nearly $84 \%$ of cases, the anatomical position of the appendix was easily recognized by a perfectly augmented field of the appendix site with laparoscopy (Figure 2), while it was difficult in $16 \%$ of cases because of the position of the appendix, adhesions, and complications or missed diagnosis. The majority of operations were simple, straightforward to a mild difficult because of the position of the appendix (Table 1). The anatomical position distribution of the appendix is shown in Table 2 and Figures 2 and 3.

Table 1: Summary of operation findings during appendicetomy.

\begin{tabular}{lcccccc}
\hline \multicolumn{1}{c}{ Appendix pathology } & No. & $\%$ & $\begin{array}{c}\text { Conversion } \\
\text { Cases }\end{array}$ & $\begin{array}{c}\text { Causes of } \\
\text { conversion }\end{array}$ & $\begin{array}{c}\text { Average } \\
\text { duration/mint }\end{array}$ & P value \\
\hline $\begin{array}{l}\text { Simple appendicitis } \\
\text { operation }\end{array}$ & 124 & 83.78 & $2(1.6 \%)$ & Technical & $34.6(\mathrm{SD} \pm 5.5)$ & \\
$\begin{array}{l}\text { Complicated appendicitis } \\
\text { operation }\end{array}$ & 24 & 16.22 & $5(20.8 \%)$ & Various & $51.2(\mathrm{SD} \pm 11.9)$ & $<0.001^{*}$ \\
\begin{tabular}{l} 
Total \\
\hline
\end{tabular} & 148 & 100.0 & $7(4.7 \%)$ & Various & 42.9 & \\
\hline
\end{tabular}

*Laparoscopically, a highly significant variation in (duration) was observed between simple appendicitis and complicated appendicitis operations by using $t$ test.

Table 2: Appendectomies variability according to the anatomical site of the appendix.

\begin{tabular}{lcccccc}
\hline $\begin{array}{l}\text { Appendix anatomical } \\
\text { site }\end{array}$ & No. & $\%$ & $\begin{array}{c}\text { Conversion } \\
\text { Cases }\end{array}$ & $\begin{array}{c}\text { Causes of } \\
\text { conversion }\end{array}$ & $\begin{array}{c}\text { Average } \\
\text { duration/Mint. }\end{array}$ & $\boldsymbol{P \text { value }}$ \\
\hline Anterior group $\wedge$ & 47 & 31.75 & $2(4.2 \%)$ & Various & $44.6(\mathrm{SD} \pm 6.6)$ & \\
Posterior group $\wedge \wedge$ & 101 & 68.24 & $5(4.9 \%)$ & Various $^{\star *}$ & $51.5(\mathrm{SD} \pm 11.8)$ & $<0.001^{*}$ \\
Total & 148 & 100.0 & $7(4.7 \%)$ & Various $^{* * *}$ & 42.9 & \\
\hline
\end{tabular}

*Laparoscopically, a highly significant variation in (duration) was observed between the anterior group and posterior group by using $t$ test. $\wedge$ includes Preileal, Subileal, and Subhepatic and pelvic groups. $\wedge \wedge$ includes Retrocecal Subcecal and paracecal groups. ${ }^{* *}$ Various causes of conversion include Mass, Ovarian Mass, and Hematoma. ${ }^{* * *}$ Various causes of conversion include Slipped ligature, viscous tear, and additional pathologies.

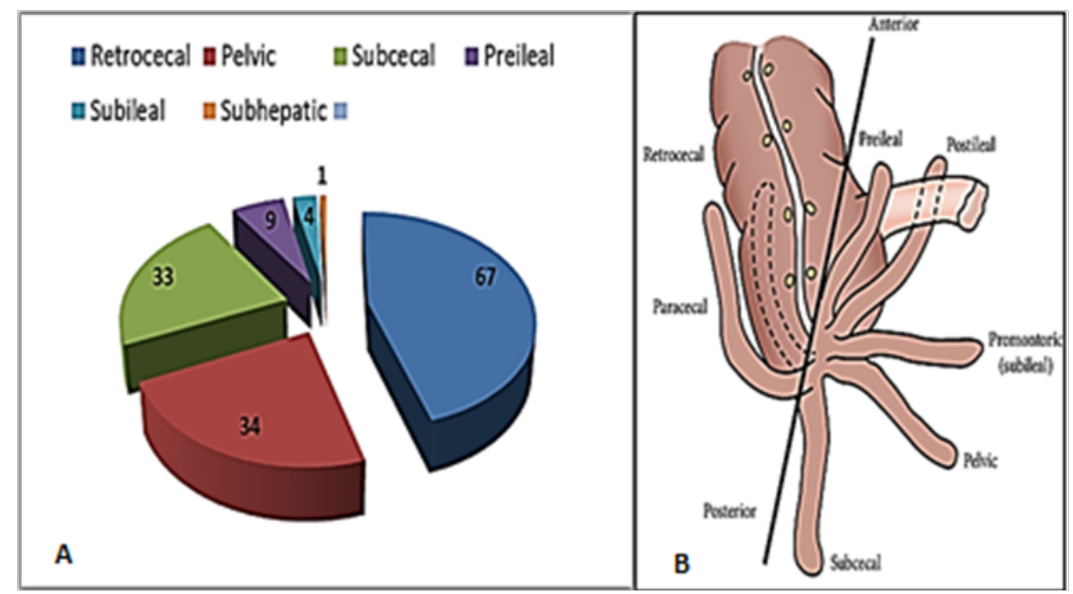

Figure 2: (A) Resulted appendix positions graph. (B) Various positions known vermiform appendix anatomical positions (Adapted from O'Connor and Reed ${ }^{9}$ ). 
Various positions of the appendix were not difficult for laparoscopic operation. Statistical analysis of the results using independent-sample t-test indicates moderate difficulties were met due to distended small bowel loops, omentum adhesion, bleedings, secondary pathologies, and other technical causes (Figure 3 to 5).
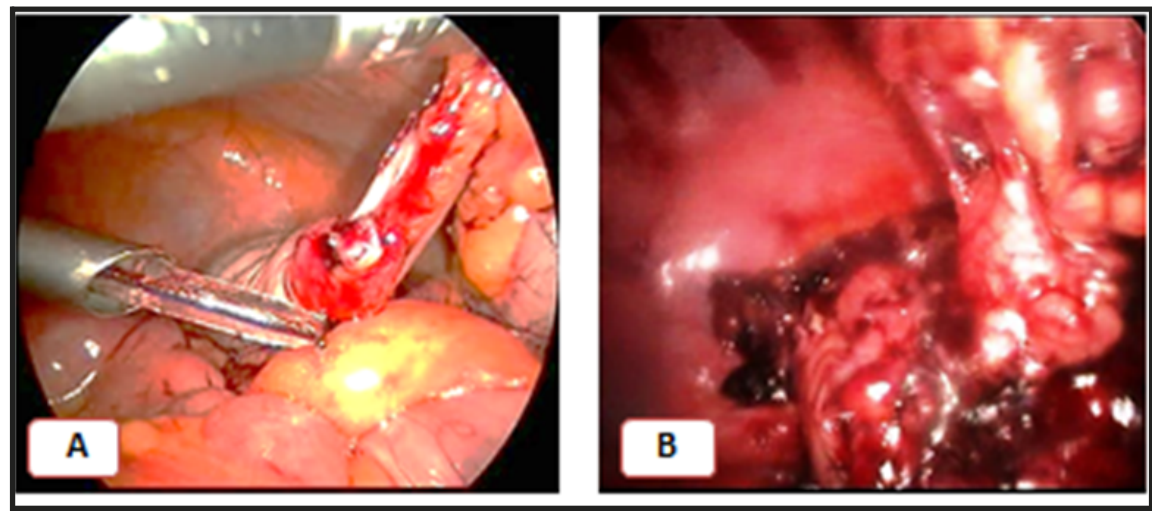

Figure 3: Laparoscopic management of both (A) Early and (B) advanced of complicated acute appendicitis management.

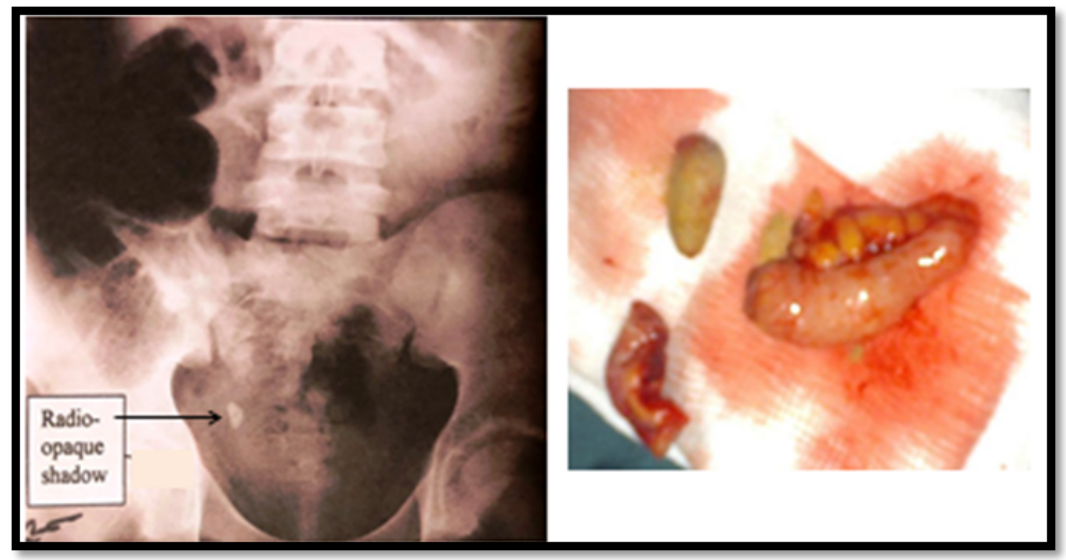

Figure 4: Plain X-ray film and laparoscopic findings of a 17 years patient with highly suspicious of acute appendicitis, but the radiopaque shadow in the ureteric course caused confusion that had been solved by laparoscopy.

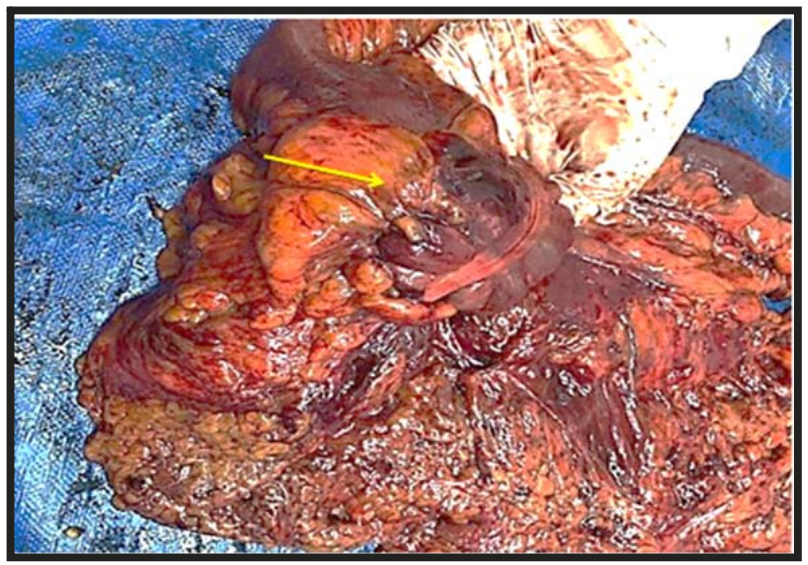

Figure 5: En bloc resection of ileocecal junction due to complicated Crohn's disease burred appendix (yellow arrow). 
Duration of operations was 34-60 minutes, with an average of 42.9 minutes (Table 1 ). However, statistically, the differences were found to be significant between the two groups within the present study $(P<0.001)$, in which the average time was longer in complicated operation cases, about 16.6 minutes, than the simple operation cases. The operation outcome accordingly is more affected by the advanced complex pathologies rather than anatomical positions of the inflamed appendix. Difficulties were also observed by posterior appendicular groups (retrocecal and subcecal) that represented by average duration, which was longer in posterior group cases (about 7 minutes) than the anterior group $(P<0.001)$, as shown in Table 2. Postoperative pain was low as much as $3 \%$ due to diaphragmatic residual $\mathrm{CO} 2$ irritation radiating to the shoulder relieved by diclofenac $75 \mathrm{mg}$ within 2-3 hours. Other incisional pain was very slight as the appendicular bed and port sites were infiltrated by local anesthesia (Buivacaine $0.5 \%-10 \mathrm{ml}$ ) postoperatively. The conversion rate was $4.7 \%$ (Table 1 and 2). In seven cases, conversions were needed for laparotomy. A case of ileocecal tumor (lymphoma) presented acutely by appendicitis features needed conversion later on. A 34 years female case of perforation of ileum occurred by technical fault and needed conversion to open management. Another case of 29 years old male patient with late toxic appendicular mass ended in cecal perforation during manipulation by laparoscopic approach and was converted to open method (Figure 4). Another case of conversion was 26 years male case of pelvic hematoma changed to open after one week. A case of 18 years boy diagnosed with Crohn's disease was secondarily reopened for excision of the terminal part of the ileum and ascending colon. Another case complicated by a slipped ligature from appendicular stump was managed conservatively for two weeks by putting a tube drain (Table 1). Regarding hospital stay, $30 \%$ of cases were discharged on the same operative day, $50 \%$ on the $1^{\text {st }}$ postoperative day, and $20 \%$ discharged on the $2^{\text {nd }}$ postoperative day. Postoperative complications were $3 \%$ and were mild to moderate (pelvic hematoma, port infection, and bleeding). Returning to work was during 8-10 days postoperatively. Regarding the cases with findings of more than one pathologies, a case of old perforated duodenal ulcer had been diagnosed as acute appendicitis and was managed by the same session of laparoscopy successfully. Ten cases of various types of ovarian cysts, complicated ( 4 cases) and noncomplicated (6 cases), were observed and managed the same while, in addition to appendectomy. In one of the cases, laparoscopic appendicectomy was impossible because of Crohn's disease (Figure 5).

\section{Discussion}

Although laparoscopic appendicectomy started to enter surgical fields since the 1980s, controversies about this procedure are still not well settled to a definite, proper pole. Various results of numerous randomized studies agreed that the progressions of technologies hugged the development of laparoscopies in the field of surgery which has predictable medical innovations in the last three decades. The consequence of this has been a shift from purely disease-oriented surgical management to a more patient-oriented approach. ${ }^{3,7,13}$ Anyhow, by this study, we observed that endoscopic surgery is both a disease and a patient-oriented technique. With other research, evident minimal invasive surgical techniques in the experienced hands have had majestic consequences for patient and surgeon safety scales. ${ }^{14-16}$ In general, this study results agree with the vast majority of studies that practicing laparoscopic surgeries taught us to explain the old impression about the idea that large problems require large incisions is nearly changed. In another way, big problems need bigger visual horizons, and still, there 
is little room for "key-hole" surgery for palpating and dealing with organs manually. Instead, this had been replaced by instruments. Moreover, the wider visual field of laparoscopy than naked eye vision regressed the idea of the old "key-hole" theory. ${ }^{13-17}$ Regarding controversial ideas in the world, literature is just minority and old early era of laparoscopic appendectomy, that still not observed any advantage of laparoscopic appendectomy on open appendectomy and prefer manual palpation on instrumental sensation and endoscopic vision in the management of acute appendicitis moreover to small open incisions in majority of appendicitis. However, in our study, we proved that the open appendectomy is nearly narrow vision surgery in which only partially one can feel an inflamed appendix and no more in opposite to wider endoscopic visual field. ${ }^{14,18}$ Now after retaining experiences in the procedure of lap-appendectomies, the operative duration is inclined. The procedure became more accepted and popular for both patients and surgeons as this procedure has better various views of advances over minute disadvantages. This is also documented by Moberg and Montgomery cited in Çiftçi study. In their review of literature, they concluded that the greatest benefits of the laparoscopic technique are that it causes less trauma, the diagnostic accuracy is better, and the cosmetic result is superior to that after a conventional operation; this is all at the price of a longer operation time. ${ }^{14,15}$ Although we observed with the advanced experiences, the duration also became not significantly longer than open appendectomy, as it was on average nearly 45 minutes. Better visualization of intra-abdominal views is the major indication and preference on laparoscopic appendectomy as proved by Minutolo et al. that the new area of the potential benefit of laparoscopy is its ability to be diagnostic, especially with reference to gynecological conditions. A study looking at unnecessary appendectomies in women found that in situations where a healthy-looking appendix was found, and a gynecological diagnosis existed, open appendectomy had a 7-fold increased risk of removing the appendix while only making the gynecological diagnosis in $17 \%$ of its patients, versus $73 \%$ with laparoscopic appendectomy patients. However, an Italian study proved that in an Italian Consensus Conference, $60 \%$ of surgeons felt that the best practice is to remove normal-looking appendices as Phillips et al. found that $1 / 3$ of all "normal looking appendices" will actually be inflamed when examined histologically. ${ }^{10,12,16,19,20}$ In our study, we observed controversial cases of acute appendicitis with complicated ovarian cysts but histopathologically confirmed acute appendicitis, and this is established by many studies. ${ }^{21,22}$ Furthermore, a study by Switzer, Gill and Karmali verified that laparoscopic appendectomy is practicable and has advantages over open appendectomy under certain interrogating circumstances. ${ }^{19,20}$ These advantages are most evident in the young female, the working patient, and the obese patient. However, overall, the advantages of laparoscopy are, at best, modest and clinical benefit is not always demonstrable. ${ }^{19,21}$ Anyhow, we found in this study that laparoscopic appendicectomy proved nowadays is the most applicable and confident for difficult curious situations of inflammation and sequences of acute appendicitis with other intra-abdominal pathologies, as the laparoscopic appendectomy plays both diagnostic and therapeutic roles. ${ }^{22,23}$ In these equivocal cases during laparoscopy, the process of laparoscopic appendectomy had been given another advantage to this approach which is also evidenced by Vettoretto and Agresta, ${ }^{16}$ that they agreed that laparoscopy allows for superior visualization of the peritoneal cavity and exclusion of other pathology when the diagnosis of appendicitis is equivocal. ${ }^{17,18,22,23}$ For this reason, 
laparoscopic appendectomy is often the preferred operation in women of childbearing age, in which the differential diagnosis for appendicitis is especially broad. ${ }^{14,17}$ On the other hand, a retrospective study by Sazhin et al. $^{17}$ designed laparoscopic appendectomy advantages because of duration, accuracy, and stay in the hospital, moreover to certain pre-operative factors. ${ }^{16,19,22}$ In this study, only $4.7 \%$ conversion rate was recorded, but the last few studies giving $9.7 \%$ and $8.7 \%$ for the conversion rate from laparoscopic appendectomy to open appendectomy and explaining that the older patients have a higher likelihood of conversion with severe acute inflammation being the most common reason for conversion. Additional minimally invasive fellowship training was the only surgeon-specific factor that significantly impacted the conversion rate. It also identified that higher levels of C-reactive protein were associated with increased conversion rates. ${ }^{20,23}$ Accordingly, they have developed a scoring model to estimate the risk of conversion to open during laparoscopic appendectomy based on clinically relevant and readily available pre-operative patient characteristics, including age $\geq 40$, male sex, black race, diabetes, obesity, and a pre-operative diagnosis of complicated appendicitis. ${ }^{19,20,24}$ Nevertheless, we did not observe the factors mentioned by the previous study other than few cases of moderately complicated mass which indebted laparotomy. An important point here to be encysted is that putting camera port and two manipulating ports on midline camera supra-umbilical, sub-umbilical and suprapubic position were very helpful to deal with any other peripheral secondary noncomplicated conditions. ${ }^{20,24,25}$ Conclusively, our study results agree with most of the other studies worldwide that in cases of well chosen clinical situation, complication points of view, and economically in addition to doubtful cases, laparoscopic appendectomy is the option of choice for the management of such a case. ${ }^{12,14,17,19,20,22-25}$

\section{Conclusion}

By introducing laparoscopic appendicectomy in the management of acute appendicitis, which is the most common emergency non traumatic operation in our area, the outcomes progressed to be safer, less complicated, and less bedridden, in addition to better economic reservation advantages. This study proved that this minimally invasive surgery could manage the majority of cases except for some coincidental secondary pathologies. Additionally, laparoscopy in suspected cases has both diagnostic and therapeutic roles.

\section{Competing interests}

The authors declare no competing interests.

\section{References}

1. Maghrebi $H$, Maghraoui $H$, Makni $A$, Sebei $A$, Fredj SB, Mrabet $A$, et al. The use of the Alvarado score in the management of right lower quadrant abdominal pain in the adult. J Visc Surg 2010; 147(2):40-4.

2. Benabbas R, Hanna M, Shah J, Sinert R. Diagnostic accuracy of history, physical examination, laboratory tests, and point-of-care ultrasound for pediatric acute appendicitis in the emergency department: A systematic review and meta-analysis. Acad Emerg Med 2017; 24(5):523-51.

3. Ali R, Khan MR, Pishori T, Tayeb M. Laparoscopic appendectomy for acute appendicitis: Is this a feasible option for developing countries? Saudi J Gastroenterol 2010; 16(1):25-9.

4. Magdeburg R, Kahler G. New ways in the surgery of acute appendicitis? Zentralbl Chir 2013; 138(3):284-8.

5. Jaschinski $T$, Mosch CG, Eikermann M, Neugebauer EA, Sauerland S. Laparoscopic versus open surgery for suspected appendicitis. Cochrane Database Syst Rev 2018; 11(11):CD001546.

6. Snyder MJ, Guthrie M, Cagle S. Acute appendicitis: Efficient diagnosis and management. Am Fam Physician 2018; 98(1): 25-33.

7. Antoniou SA, Antoniou GA, Antoniou Al, Granderath FA. Past, present, and future of minimally invasive abdominal surgery. JSLS 2015; 19(3):e2015.00052. 
8. Casarotto A, Zarantonello FR, Rebonato M. Appendectomy in women. Is the laparoscopic approach always better than the "open" approach in uncomplicated appendicitis? Surg Laparosc Endosc Percutan Tech 2014; 24(5):406-9.

9. Ximenes AM, Mello FS, Lima-Júnior ZB, Ferreira CF, Cavalcanti AD, Dias-Filho AV. Hospitalization time after open appendectomy by three different surgical techniques. Arq Bras Cir Dig 2014; 27(3):188-90.

10. Minutolo V, Licciardello A, Stefano BD, Arena M, Arena GO, Antonacci V. Outcomes and cost analysis of laparoscopic versus open appendectomy for treatment of acute appendicitis. BMC Surg 2014; 14:14.

11. Tiwari MM, Reynoso JF, Tsang AW, Oleynikov D. Comparison of outcomes of laparoscopic and open appendectomy in management of uncomplicated and complicated appendicitis. Ann Surg 2011; 254(6):927-32.

12. Gavriilidis P, Angelis DN, Katsanos K, Saverio DS. Acute appendicectomy or conservative treatment for complicated appendicitis (phlegmon or abscess)? A systematic review by updated traditional and cumulative meta-analysis. J Clin Med Res 2019; 11(1):56-64.

13. Li X, Zhang J, Sang L, Zhang W, Chu Z, $\mathrm{Li} X$, et al. Laparoscopic versus conventional appendectomy--a meta-analysis of randomized controlled trials. BMC Gastroenterol 2010; 10:129.

14. Çiftçi F. Laparoscopic vs. mini-incision open appendectomy. World J Gastrointest Surg 2015; 7(10):267-72.

15. Khalil J, Muqim R, Rafique $M$, Khan $M$. Laparoscopic versus open appendectomy: a comparison of primary outcome measures. Saudi J Gastroenterol 2011; 17(4):236-40.

16. Vettoretto N, Agresta F. A brief review of laparoscopic appendectomy: the issues and the evidence. Tech Coloproctol 2011;15(1):1-6.

17. Sazhin AV, Mosin SV, Kodzhoglian AA, Medoev VV, Mirzoian AT, luldoshev AR, et al. The Minimal Surgical Access for Appendectomy and Complication of the Acute Appendicitis. Khirurgiia (Mosk) 2012; 65-72.

18. Clarke T, Katkhouda N, Mason RJ, Cheng BC, Olasky J, Sohn HJ, et al. Laparoscopic versus open appendectomy for the obese patient: a subset analysis from a prospective, randomized, double-blind study. Surg Endosc 2011; 25(4):1276-80.

19. Switzer NJ, Gill RS, Karmali S. The Evolution of the Appendectomy: From Open to Laparoscopic to Single Incision. Scientifica (Cairo) 2012; 2012:895469.

20. Finnerty BM, Wu X, Giambrone GP, Gaber-Baylis LK, Zabih R, Bhat A, et al. Conversion-to-open in laparoscopic appendectomy: A cohort analysis of risk factors and outcomes. Int J Surg 2017; 40:169-75.
21. Louis MA, Doubleday AR, Lin E, Baek Y, Andoni $A$, Wang $X$. Abdominal Pain in the Female Patient: A Case of Concurrent Acute Appendicitis and Ruptured Endometrioma. Case Rep Surg 2016; 2016:2156148.

22. Abe T, Nagaie T, Miyazaki M, Ochi M, Fukuya T, Kajiyama K. Risk factors of converting to laparotomy in laparoscopic appendectomy for acute appendicitis. Clin Exp Gastroenterol 2013; 6:109-14

23. Wakimoto $M$, Miller R, Shafy SZ, Tumin D, Veneziano G, Tobias JD. Safety of Same-Day Discharge Compared to Overnight Observation Following Laparoscopic Appendectomy in the Pediatric-Aged Patient: A National Surgical Quality Improvement Program Project. J Laparoendosc Adv Surg Tech A 2019; 29(7):965 -9 .

24. Sakpal SV, Bindra SS, Chamberlain RS. Laparoscopic appendectomy conversion rates two decades later: an analysis of surgeon and patient-specific factors resulting in open conversion. J Surg Res 2012; 176(1):42-9.

25. Domene CE, Volpe P, Heitor FA. Three port laparoscopic appendectomy technique with low cost and aesthetic advantage. Arq Bras Cir Dig 2014; 27(Suppl 1):73-6. 